\title{
Influence of Flettner balloon, used as wind energy capturing system, on container ship stability
}

\author{
Mihail-Vlad Vasilescu ${ }^{1, *}$ and Dumitru Dinu ${ }^{1}$ \\ 1 Constanta Maritime University, Doctoral School of Mechanical Engineering, str. Mircea cel Batran, \\ No. 104, ZC 900663, Constanta, Romania
}

\begin{abstract}
This article presents the influence on the stability of a container ship, by connecting a Flettner balloon, as wind energy capturing system. Flettner balloon is a generator of electric power, filled with helium that rotates around a horizontal axis and sends the electricity using a cable. It rotates around a horizontal axis in response to the wind, effectively generating clean, renewable electricity at a lower cost than all competing systems. These article major points determined by the authors are: calculation of the forces which influence the balloon, calculation the influence of the balloon on the ship transverse and longitudinal stability, calculation of the ship new displacement, new draft, new GM and period of rolling. As a conclusion of the article, the reader will discover that the transverse stability of the ship will insignificant decreased with a small value of 0.01 and the longitudinal stability will be improved by 0.7532 . The article demonstrates that a Flettner balloon, installed on a container ship, is a possible concept of capturing wind energy.
\end{abstract}

\section{Introduction}

On a container ship we have installed a Flettner balloon, which is situated above the vessel, anchored with some lines. The Flettner balloon has some wind stabilizers which help him maintain his position.

The container ship initial characteristics, without Flattner balloon connected are:

$>\quad \mathrm{L}=168.56 \mathrm{~m}$;

$>\quad \mathrm{l}=29.4 \mathrm{~m}$;

$>\mathrm{D}=39449 \mathrm{mt}$

$>\mathrm{GM}=4.32 \mathrm{~m}$;

$>T_{p}=9.56 \mathrm{~m}$;

Corresponding author: vladmihail 2005@yahoo.com 


\section{Where:}

$\mathrm{L}=$ Length of the ship; $\mathrm{l}=$ Berth of the ship; $\mathrm{D}=$ Displacement; $\mathrm{GM}=$ Metacentric height is a measurement of the initial static stability of a floating body. It is calculated as the distance between the centre of gravity of a ship G and its metacentre M. $T_{p}=$ Ship draft.

Due to high altitude at which the Flettner balloon rises and because of the helium gas, the forces which appear in the balloon are:

$F_{a}=$ Lifting force; $G_{H e}=$ Helium weight which is inside the balloon; $G_{B}=$ Balloon weight structure; $G_{c p}=$ Electrical cables and mooring lines weight.

By using Computational Fluid Dynamics (CFD) we can visualize the velocity and pressure distribution around the section of the Flettner balloon.

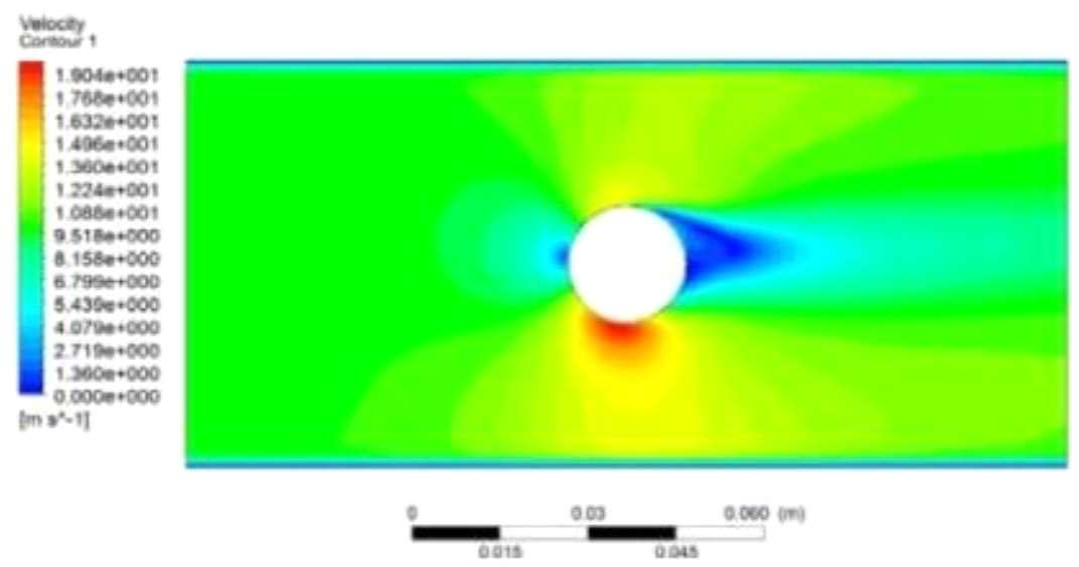

Fig.1. Velocity around the section of Flettner balloon with circulation [1]

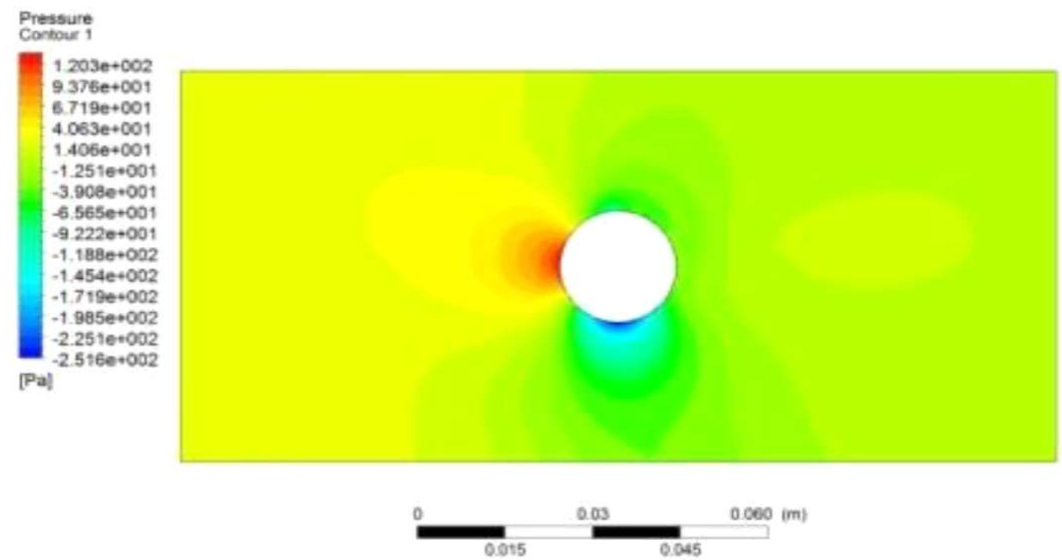

Fig.2. Pressure distribtion around the section of Flettner balloon with circulation [1] 


\section{Calculation of the ship draft at the new displacement D}

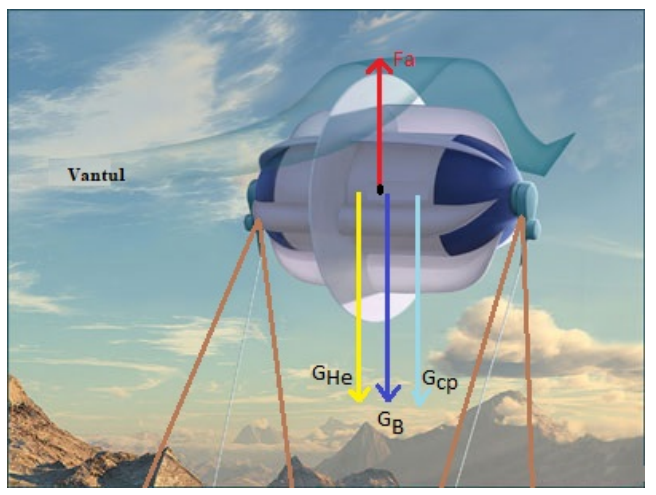

Fig. 3. The forces which appear and influence the lifting of the balloon[2]

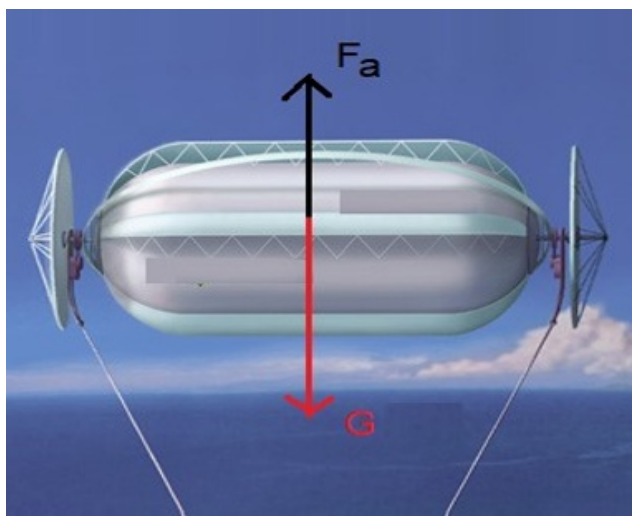

Fig. 4. The merged forces which appear and influence the lifting of the balloon[3]

$$
\begin{aligned}
& F_{a}=\rho_{A} V_{b} g=2528.4 k N=2528400 \mathrm{~N} \\
& G=G_{H e}+G_{B}+G_{c p}=m g \\
& \mathrm{~m}=12.626 \mathrm{t} \\
& G=m g=12.626 \times 9.8=123.7348 \mathrm{kN}=123734.8 \mathrm{~N} \\
& F_{a}^{\prime \prime}=F_{a}-G \cong 245 \mathrm{mt}
\end{aligned}
$$

Where:

$F_{a}^{\prime \prime}=$ Resulting lifting force, with the extracted value of the weights; $\mathrm{m}=$ mass; $\mathrm{g}=$ gravitational acceleration; $\rho_{A}=1.29 \frac{\mathrm{kg}}{\mathrm{m}^{3}}=$ water density; $V_{b}=200000 \mathrm{~m}^{3}=$ balloon volume;

\subsection{Calculation of the new displacement $D^{\text {' }}$}

$$
D^{\prime}=D-F_{a}^{\prime \prime}=39204 m t
$$


$D^{`}=39204 m t$

By interpolation from hydrostatic tables we extracted the immersion value - TPC.

For any draft is the mass which must be loaded or discharged to change a ship's mean draft in water by one centimetre.

$T P C=45.39 \mathrm{mt}$

$$
D^{`}-D_{9.50}=14.78 m t
$$

New draft $T_{p}^{\prime}=9.50+\frac{D^{`}-D_{9.50}}{T P C} \times 0.01=9.5032 m$

\section{Determination of the ship transverse stability}

\subsection{Calculation of KG}

$$
G M=K M-K G
$$

Where:

$G M=4.32 \mathrm{~m}$;

$T K M=12.32 \mathrm{~m}=>K G=8 \mathrm{~m}$

Where:

$\mathrm{KG}=$ The distance from keel $\mathrm{K}$ to $\mathrm{G}$ center of gravity;

\subsection{Calculation of TKM for the new draft}

$T_{p}^{\prime}=9.5032 m$

By interpolation from hydrostatic tables we extracted the TKM and LKM for $T_{p}^{\prime}$. $T K M^{`}=K M_{T}=12.31 \mathrm{~m}$

Where:

Transverse metacentre $=$ The point of intersection of the vertical through the centre of buoyancy of a ship in the position of equilibrium with the vertical through the new centre of buoyancy when the ship is slightly heeled.

$\mathrm{TKM}=$ Transverse stability. The distance between the keel $\mathrm{K}$ and the tranverse metacenter $\mathrm{M}$;

\subsection{Calculation of new GM (Metacentric height)}

$$
\begin{aligned}
& \mathrm{KG}=8 \mathrm{~m} \\
& \quad G M^{\prime}=K M_{T}-K G=4.31 \mathrm{~m}
\end{aligned}
$$

\subsection{Determination of the initial righting lever GZ [Fig.5]}

Transverse statistic stability is a term used to describe the ability of a ship to return to the upright position when it has been forcibly heeled by an external force and is momentarily at rest when floating in still water.[4]

$\mathrm{GZ}=$ Righting lever. It is defined as the horizontal distance, measured in meters, between the centre of gravity $\mathrm{G}$ and the vertical line of action of the buoyancy force Bf, acting through the centre of buoyancy B when the ship is heeled. 
The righting moment at any angle of heel represents the instantaneous value of the ship's ability to return to the upright position, when the ship is in still water conditions and is momentarily at rest. It is expressed in tonnes-meter.

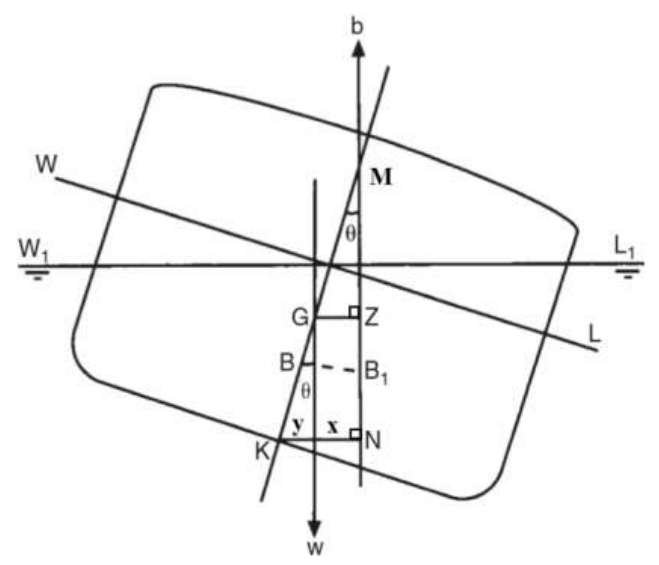

Fig. 5. Ship Stability initial condition

$$
\begin{aligned}
& K N=x+y \\
& x=G Z \\
& y=K G x \sin \theta \\
& K N=G Z+K G x \sin \theta \\
& G Z=K N-K G x \sin \theta \\
& G M=4.32 m ; D=39449 m t
\end{aligned}
$$

Where:

$\theta=$ Angle of heel; $\mathrm{GZ}=$ Right lever; $\mathrm{B}=$ Centre of buoyancy before trimming; $B_{1}=$ Centre of buoyancy after trimming; $\mathrm{KG}=$ Distance from keel $\mathrm{K}$ to the centre of gravity $\mathrm{G} ; \mathrm{GM}=$ Metacentric height, it is a measurement of the initial static stability of a floating body. It is the distance between the centre of gravity $\mathrm{G}$ of a ship and its metacentre M. KN=Being the righting lever measured from the keel $\mathrm{K} ; \mathrm{WL}=$ Water line;

$\mathrm{w}=$ Weight; $\mathrm{KM}=$ Distance from keel $\mathrm{K}$ to the metacenter $\mathrm{M}$.

Table 1. GZ calculated for different values of the $\theta$ angle from 0 to 90 .

\begin{tabular}{|c|c|c|c|c|c|}
\hline$\theta$ & $\operatorname{Sin} \theta$ & $\mathbf{K G}$ & $\mathbf{K N}$ & $\mathbf{K G} \mathbf{x} \sin \theta$ & $\mathbf{G Z}$ \\
\hline 0 & 0.000 & 8 & 0.000 & 0.000 & 0.000 \\
\hline 10 & 0.174 & 8 & 2.113 & 1.392 & 0.721 \\
\hline 20 & 0.342 & 8 & 4.260 & 2.736 & 1.524 \\
\hline 30 & 0.500 & 8 & 6.310 & 4.000 & 2.310 \\
\hline 40 & 0.640 & 8 & 7.830 & 5.120 & 2.710 \\
\hline 45 & 0.707 & 8 & 8.396 & 5.656 & 2.740 \\
\hline 50 & 0.766 & 8 & 8.828 & 6.128 & 2.700 \\
\hline 60 & 0.866 & 8 & 9.330 & 6.928 & 2.402 \\
\hline 70 & 0.939 & 8 & 9.332 & 7.512 & 1.820 \\
\hline 80 & 0.984 & 8 & 8.892 & 7.872 & 1.020 \\
\hline 90 & 1.000 & 8 & 8.010 & 8.000 & 0.010 \\
\hline
\end{tabular}


The transverse stability curve is plotted on the graph with black (Fig.7). The values from table 1 are taken from KN cross curves of ship stability booklet.[5]

\subsection{Calculation of the new G'Z` [Fig.4]}

$$
\begin{aligned}
& G M^{\prime}=4.31 \mathrm{~m} \\
& D^{\prime}=39204 \mathrm{mt} \\
& K N=x^{\prime}+y^{\prime} \\
& x^{\prime}=G^{\prime} Z^{\prime} \\
& y^{\prime}=K^{\prime} x \sin \theta \\
& K^{\prime}=G^{\prime} Z^{\prime}+K G^{\prime} x \sin \theta \\
& G^{\prime} Z^{\prime}=K^{\prime}-K G^{\prime} x \sin \theta
\end{aligned}
$$

Where:

$\mathrm{G}^{`} \mathrm{Z}^{\prime}=$ Right lever; $K \mathrm{G}^{`}=$ Distance from keel to the new center of mass/gravity; $\mathrm{G}^{`} \mathrm{Z}^{`}=\mathrm{New}$ right lever after the center of gravity moved; $\mathrm{G}^{\prime} \mathrm{M}=\mathrm{New}$ metacentric height, it is a measurement of the initial static stability of a floating body. It is the distance between the centre of gravity $\mathrm{G}^{\prime}$ of a ship and its metacentre $\mathrm{M}$.

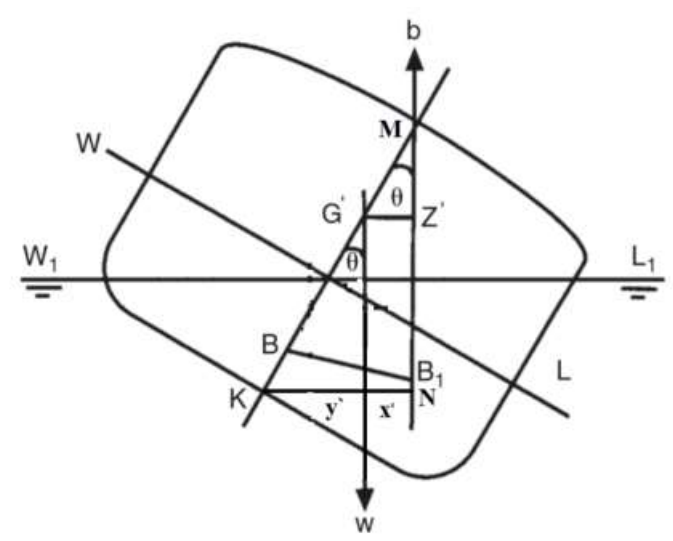

Fig. 6. Ship Stability condition after the connection of Flettner balloon

Table 2. G' $Z^{\prime}$ calculated for different values of the $\theta$ angle from 0 to 90 .

\begin{tabular}{|c|c|c|c|c|c|}
\hline$\theta$ & $\operatorname{Sin} \theta$ & $\mathbf{K G}^{`}$ & $\mathbf{K N}^{`}$ & $\mathbf{K G}^{`} \mathbf{x} \sin \theta$ & $\mathbf{G}^{\mathbf{}} \mathbf{}$ \\
\hline 0 & 0.000 & 8.01 & 0.000 & 0.000 & 0.000 \\
\hline 10 & 0.174 & 8.01 & 2.113 & 1.393 & 0.720 \\
\hline 20 & 0.342 & 8.01 & 4.250 & 2.739 & 1.511 \\
\hline 30 & 0.500 & 8.01 & 6.300 & 4.005 & 2.295 \\
\hline 40 & 0.640 & 8.01 & 7.820 & 5.126 & 2.694 \\
\hline 45 & 0.707 & 8.01 & 8.383 & 5.663 & 2.720 \\
\hline 50 & 0.766 & 8.01 & 8.825 & 6.135 & 2.690 \\
\hline 60 & 0.866 & 8.01 & 9.330 & 6.936 & 2.394 \\
\hline 70 & 0.939 & 8.01 & 9.331 & 7.521 & 1.810 \\
\hline 80 & 0.984 & 8.01 & 8.899 & 7.881 & 1.018 \\
\hline 90 & 1.000 & 8.01 & 8.010 & 8.010 & 0.000 \\
\hline
\end{tabular}


The transverse stability curve is plotted on the graph with blue ( Fig.7). The values from table 2 are taken from KN`cross curves of ship stability booklet.[5]

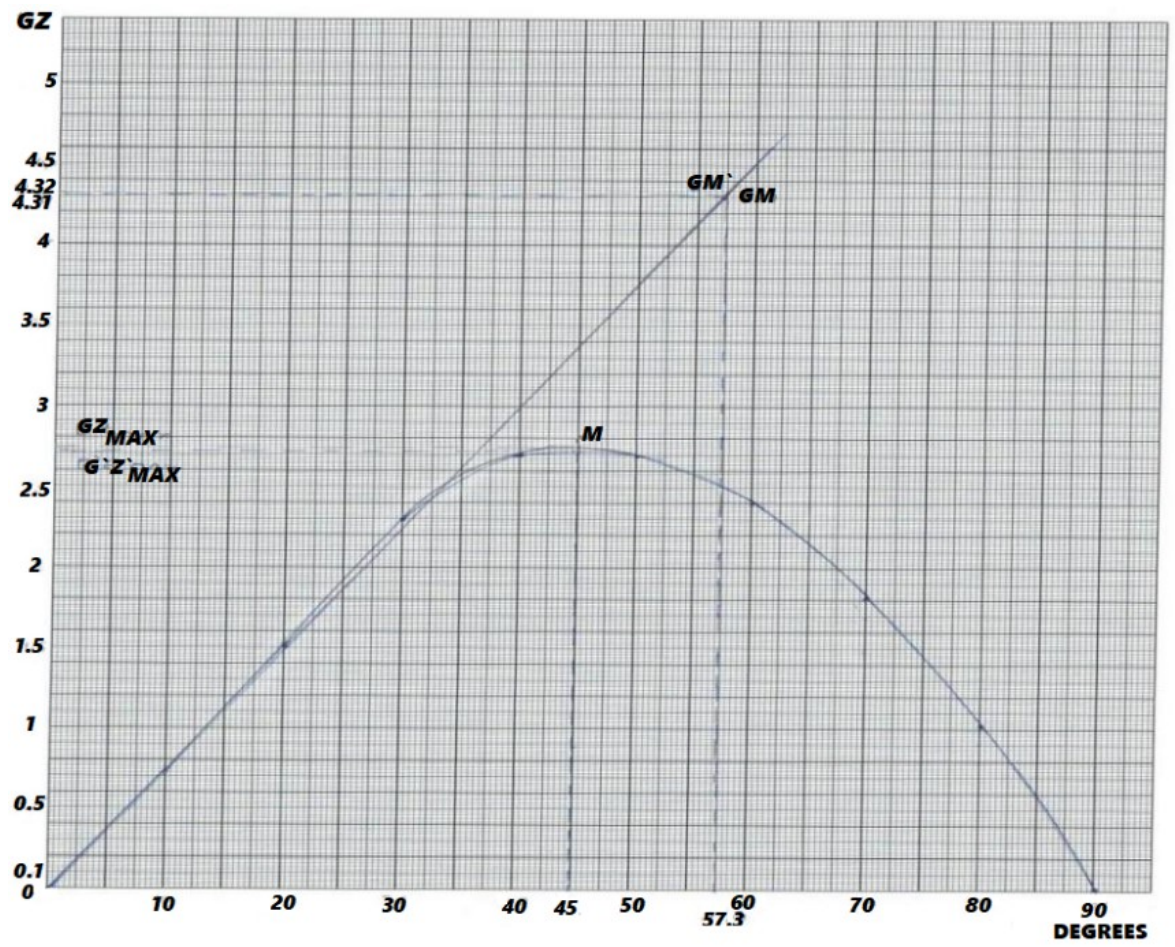

Fig. 7. Transverse stability graph

The graph represents the curve of the static stability of the ship and the variation of the stability right lever according to the variation of the transverse tilt angle of the ship. The initial stability is shown in black, without the energy generating equipment. With blue is shown the final stability, with the energy generating equipment installed.

Where:

$>$ Point $\mathrm{O}$, represents the origin of the curve;

$>$ Point $\mathrm{M}$ and $\mathrm{M}^{\prime}$, maximum point of the curve, critical angle of roll or maximum angle of canary; the point where the recovery arm has the maximum value;

$>$ For $\mathrm{GM}^{\prime}<\mathrm{GM} \quad 4.3184<4.32$ ship transverse stability is lower connection of the ship with the balloon that generates green, unconventional energy.

\subsection{Rolling period}

$T=\frac{2 x l x C}{\sqrt{G M}}$

Where:

$C=0.371$ for $T_{P}^{\prime}=9.5032 \mathrm{~m} ; G M=4.32 \mathrm{~m}$ and $G M{ }^{`}=4.31 \mathrm{~m}$

$\mathrm{T}=$ initial rolling period; $\mathrm{T}^{\prime}=$ rolling period after the connection of the ship with the balloon that generates green, unconventional energy; $\mathrm{GM}=$ Metacentric height, it is a measurement of the initial static stability of a floating body. It is the distance between the centre of gravity $\mathrm{G}$ of a ship and its metacentre $\mathrm{M} . \mathrm{GM}{ }^{`}=\mathrm{New}$ metacentric height. $T=10.4956 \mathrm{~S}$ 
and $T^{\prime}=10.5078 \mathrm{~s}$.

From the graph we can also observe that the ship has initial a slower period of rolling, comparing with the rolling period after the connection of the ship with the balloon.

$$
T<T^{\prime} \quad 10.4956<10.5078
$$

\subsection{Inclining moments of the ship}

\subsubsection{Stable wind}

$$
\begin{aligned}
& l w_{1}=\frac{0.0514 \times A \times Z}{D} \\
& l w_{1}=\frac{0.0514 \times A \times Z}{D^{`}}
\end{aligned}
$$

Where:

$\mathrm{D}=$ initial ship displacement; $\mathrm{D}^{\prime}=$ displacement of the ship, after the connection of the balloon with the ship; $\mathrm{A}=$ the wind pressure area on the hull of the ship and on the cargo on the deck above the waterline, calculated for a draft $T_{p}=9.56 \mathrm{~m}$ and a $D=39449 \mathrm{mt}$; $A{ }^{`}=$ the wind pressure area on the hull of the ship and on the cargo on the deck above the waterline, calculated for a draft $T_{p}^{\prime}=9.5032 \mathrm{~m}$ and a $D^{`}=39204 \mathrm{mt} ; \mathrm{Z}=$ vertical distance [5] between the center of A and the center of the lateral area of the keel, at a draft of $T_{p}=9.56 \mathrm{~m}$ and a $D=39449 \mathrm{mt}$;

$\mathrm{Z}^{\prime}=$ vertical distance between and the center of the lateral area of the keel, at a draft of $T_{p}^{\prime}=9.5032 m$ and $D^{\prime}=39204 m t ; T_{p}=9.56 m$ and $D=39449 m t ;$

\section{Calculation of A}

By interpolation from wind area table [5], for a draft $T_{p}=9.56 \mathrm{~m} \Rightarrow$ $A=1478.9936 \mathrm{~m}^{2}$

\section{Calculation of $\mathbf{Z}$}

By interpolation from wind area table[5], for a draft $T_{p}=9.56 \mathrm{~m}=\mathrm{Z}=10.2272 \mathrm{~m}$; $l w_{1}=0.019708 m ; T_{p}^{\prime}=9.5032 m$ and $D^{\prime}=39204 m t$

\section{Calculation of $\mathbf{A}^{`}$}

By interpolation from wind area table [5], for a draft $T_{p}^{\prime}=9.5032 \mathrm{~m}=>$

$A^{`}=1488.7313 \mathrm{~m}^{2}$

\section{Calculation of $\mathbf{Z}$}

By interpolation from wind area table[5], for a draft $T_{p}^{\prime}=9.5032 \mathrm{~m}=Z^{\prime}=10.2203 \mathrm{~m}$; $l w_{1}^{\prime}=0.019948 \mathrm{~m}$

\subsubsection{In case of a gust of wind}

$$
\begin{aligned}
& l w_{2}=1.5 x l w_{1} \\
& l w_{2}=1.5 x l w_{1} \\
& T_{p}=9.56 \mathrm{~m} \text { and } D=39449 \mathrm{mt} \\
& l w_{2}=0.029562 \mathrm{~m} \\
& T_{p}=9.5032 \mathrm{~m} \text { and } D^{`}=39204 \mathrm{mt} \\
& l w_{2}=0.029922 \mathrm{~m}
\end{aligned}
$$




\title{
4 Ship longitudinal stability and its effect on the ship trim
}

\author{
$\operatorname{MTC} 1 \mathrm{~cm}=\frac{D \times G M_{L}}{100 \times L}$ \\ Where: \\ $\mathrm{MTC}=$ moment of change trim one centimeter \\ $\mathrm{D}=$ ship displacement \\ $\mathrm{L}=$ ship length [8] \\ $G M_{L}=\mathrm{GM}$ longitudinal
}

\subsection{Determination of LKM for the new draft}

$$
T_{p}^{\prime}=9.5032 m
$$

By interpolation from hydrostatic tables we extracted the LKM for $T_{p}^{\prime}$.

$L K M=K M_{L}=232.9952 \mathrm{~m}$

Where:

Longitudinal metacenter $=$ The point in a vertical line through the centre of gravity of a ship where this line is intersected by a second vertical line through the centre of buoyancy when the ship is inclined at a very small angle in a fore and aft direction. LKM= Longitudinal stability. The distance between the keel $\mathrm{K}$ and the longitudinal metacenter $\mathrm{M}$; [9]

\subsection{Calculation of the MTC' for $T_{p}^{\prime}=9.5032 \mathrm{~m}$}

By interpolation in hydrostatic tables at $T_{p}^{\prime} \Rightarrow M T C^{\prime}=530.3664 \mathrm{mt} \times \mathbf{m}$

$M T C^{\prime}=$ Final MTC $^{\prime}$ after the connection of the balloon with the ship $M T C=531.92 m t \times m$

We can observe that:

$$
\text { MTC }>\text { MTC } \quad 531.92>530.3664
$$

\subsection{Calculation of initial $G M_{L}$}

$$
G M_{L}=\frac{M T C \times 100 \times L}{D}=227.2810
$$

\subsection{Determination of $G M_{L}$}

$$
\begin{aligned}
& M T C 1 \mathrm{~cm}=\frac{D \times G M_{L}^{\prime}}{100 \times L} \\
& G M_{L}^{\prime}=\frac{M T C^{\prime} \times 100 \times L}{D^{`}}=228.0342
\end{aligned}
$$

Because $G M_{L}<G M_{L}^{\prime} \quad 227.281<228.0342$ it means that the longitudinal stability of the ship, after the connection of the Flettner balloon has been improved. Thus we have reduced the effect of stresses affecting the longitudinal axis of the ship. 


\section{Conclusions}

From this paper we can see that the Flettner balloon connected to the ship in not influencing to much the ship stability.

From the stability point of view, transverse stability has decreased:

$G M{ }^{`}<G M$

$4.31<4.32$

but the value is insignificant.

Longitudinal stability of the ship, after the connection of the balloon, was improved: $G M_{L}^{\prime}>G M_{L}$

$228.0342>227.2810$

After the connection of the ship with the balloon, we can observe that the rolling period has been increased:

$T^{\prime}>T$

$10.5078>10.4956$

By connecting the Flettner balloon to the ship main deck, the ship will be taken out from the water, GM will be slightly reduce by 0.01 because the center of gravity $G$ will rise. The righting lever GZ will be reduced.

Above study we demonstrate that the installation of a Flettner balloon on a container ship, is a possible method of reducing fossil fuel consumption and greenhouse gas emissions. The study also proves that a Flattner balloon installed on a container ship with the above characteristics is safe for navigation.

\section{References}

1. A. A. Scupi, Magnus effect studied with analytical and numerical methods, JMTE, 1, Nautica, Constanta, 41 (2017), ISSN 18844-6116.

2. https://www.betterworldsolutions.eu/10-amazing-wind-turbines/magenn-mars-wind-tur bine/, accessed on: 05 January 2020.

3. https://techaneesh.blogspot.com/2012/08/magenn-air-rotor-system-marsmars-is-new.ht ml, accessed on: 05 January 2020.

4. B. Barras, D. Derrett, Ship Stability (Masters and Mates), sixth edition, Elsevier, London, 84 (2006).

5. Hakodate Shipyard, Manual of Stability, Japan, 56 (2003).

6. M. Rhodes, Ship Stability for Mates/Masters, Seamanship International Ltd, Glasgow, 58 (2003).

7. W. Wawrzyński, P. Krata, Method for ship's rolling period prediction with regard to non-linearity of GZ curve, J.T.A.M. 54(4), 1329-1343 (2016), DOI: https://doi.org/10.15632/jtam-pl.54.4.1329.

8. M.V. Vasilescu, M. Panaitescu, F.V. Panaitescu, C. Panait, Choose the best electricity sources for a container ship, by using a hybrid optimization model for electric renewable , SPIE Proc. Advanced Topics in Optoelectronics, Microelectronics and Nanotechnologie (to be published).

9. A. Maruccia, Optimisation model for a ship's hybrid energy system with a Flettner rotor, Master thesis, 1, 81(2019). 